\title{
The Regionalisation of the Counter Hegemon: A Response to Hassink, Gong and Marques
}

We fully agree with Hassink, Gong and Marques (this issue) that Anglophone economic geography confers dominant power. We also agree that this hegemony narrows the way in which we see non-Anglophone part of the world. We doubt, however, that a search for different traditions within non-Anglophone academia will actually yield something that could be used to form a counter-hegemon. Instead, we argue that it is location that matters, not language. The counter hegemon should be constructed, not through a plea for diversity in Anglo-American academia, but through the formation of academic communities in other international regions. We will illustrate this with some examples from South Korea and East Asia, areas with which the three authors of this commentary are especially familiar.

As Hassink, Gong and Marques argue, different places have different research cultures. As in China (the region they discuss), in South Korea the link between economic geography and regional policy has been relatively tight. There are many Korean "Departments of Regional Development," whose faculty members include geographers. Also, the planners in those departments often borrow theories from economic geography. Those who teach in these departments have many opportunities to get involved in policy-making at various levels. We also know many geographers who do academic consultancy work in real estate, tourism, planning and other areas. This is certainly a very different culture from that of Anglophone academia.

However, we doubt these cultural differences have led to the development of theories or approaches that distinguish South Korean economic geography from the Anglophone kind. One might think that, since academic consultancy enables scholars to test out theories within 
real-world settings, it would therefore help them modify and improve upon theories that South Korean academics have adopted from Anglophone academia. However, this simple model of knowledge utilisation does not hold in most cases. A policy is not a direct application of academic theory, but a combination of various elements, among which academic theory is only one (Sonn and Kang, 2016; Feser and Luger, 2003; Flanagan, Uyarra and Laranja, 2011; Benneworth, 2002; De Bruijn and Lagendijk, 2005). These complications mean that a single policy can be justified using different concepts. We can see this in action in the uneven development policies in South Korea and China. Both South Korea's national territorial policy in the 1970s and China's in the 1990s were based on an uneven development strategy. However, South Korea used growthpole (Myrdal, 1957; Hirshman, 1958; Friedmann, 1975) and spatial organisation (Barry, 1968) to justify their policy, while China used cluster (Porter, 1990) and increasing return to scale (Krugman, 1991). The two countries used different concepts because each chose a concept that was in fashion of that time.

It should be also noted from this example, that these are all well-supported concepts in Anglophone academia. Neither the Koreans nor the Chinese wanted or needed to develop their own theories to underpin their policies. In fact, it was actually considered better to use Anglophone concepts because they carry authority, while locally invented concepts would only invite criticism and unwanted debate, which would delay the policy process. Such delay can be detrimental to those academics' efficiency as academic consultants.

Hassink, Gong and Marques found that, in Brazil, economic geography research places a strong emphasis on tourism. Surely, different countries have different emphases, but does this actually result in the creation of new theories or approaches that offer unique lenses on their own issues or that have some heuristic value with regard to issues in other parts of 
the world? Hassink et al. do not argue that it does, which leads us to conclude that they could not find evidence for this in their review of their Brazilian colleagues' research.

If there are no unique approaches to be found in non-Anglophone academia, mastering plural languages will not do much to further pluralism in economic geography. Mastery of French certainly helped economic geographers during the excitement over French regulation theory. Poststructuralism and system theory were imported into Anglophone academia because they were good theories. These cases show that language barriers can only delay the import of good ideas - they cannot prevent them. If there is locally-developed theoretical tradition that is useful outside the origin, someone will eventually notice because importing a theory is a good way to promote one's career.

If there were valuable ideas in Korean academia that could be imported into Anglophone economic geography, importing those ideas would be a good way for researchers like the authors of this commentary to enhance their career in Anglophone academia. Unfortunately, we have been unable to find any such ideas so far. We are certain that Chinese academics in Anglophone academia - of whom there are many - would have done so by now, if they could. The only logical conclusion we can draw from the absence of such imports is that there is not much worth importing in the first place.

We must note here that we are not denouncing the quality of research in South Korea. We are simply pointing out that, unlike in Anglo-American academia, in South Korea and many other non-Anglophone countries, collective efforts to create new concepts, theories and approaches are rare. That is because, to build a career in South Korean academia, it is a lot more efficient to apply Anglophone theories with minor modifications than to develop one's own. Without such collective efforts, a national academia is not likely to generate theories 
and concepts that researchers from other part of the world would find useful and interesting even if individual pieces of research in that nation are decent.

As Hassink, Gong and Marques correctly point out, the globalisation of economic geography has not resulted in the formation of a pluralistic global academia. Rather, it has led to the expansion of Anglophone hegemony. While it might represent a politically correct attitude among Anglophone academics, a plea for pluralism cannot help much here because Anglophone academia is not acting as one single agent of globalisation. Rather, it comprises individual academics - and individual schools of academics - each of whom is attempting to expand her personal influence. Such efforts are welcomed by non-Anglophone researchers who want to raise their profiles within their national academies by building alliances with Anglophone scholars. In such a competitive dynamic, the actions of a small group of concerned Anglophone economic geographers who wish to promote pluralism will not take us very far.

Our proposal - and our somewhat optimistic prediction -, therefore, is that national academic communities should be integrated into groups based on their geographical proximity, a process that we call the regionalisation of academia. This idea builds upon the fact that it is human nature to be more interested in those who are geographically closer and culturally more similar to oneselves. US researchers are usually more interested in Canadian or British geography than in French or German geography. Exciting new topics, such as Japan in the 1980s or China in the 2000s, can attract interest - but such interest does not generally last long.

When referees and journal editors are not interested in specific cases, researchers are trapped between two opposite accusations: theory-less idiography and futile attempts at grand theory. When we write about a South Korean issue, if we emphasize the uniqueness of the 
case, the referees' response is often 'it's an interesting case, but it doesn't contribute to theoretical development of the field". If we emphasize the universality of our findings, referees are immediately sceptical as to whether findings from Korea can be generalised to the Anglophone world.

There is a certain degree of academic merit to these objections, but, over the course of our careers, we have come to feel that reviewers are often motivated unintentionally by a personal lack of interest in the part of the world examined in the papers they read. This lack of interest is not in evidence when the exact same material is presented to Taiwanese, Japanese and mainland Chinese colleagues. Those East Asian scholars are usually very interested in our works on South Korea and ready to seriously consider whether findings from Korean research can be applied to their own contexts or have some heuristic value for their research. Irrespective of the details, they show a lot of interest in the work. This more positive response, we believe, is based on personal feelings of proximity, not necessarily purely on the academic merits of the presentations.

Therefore, ultimately, a regionalisation of academia, based on shared biological features and history and physical proximity is a more feasible way to form an academic community beyond national borders. We might envision, for example, East Asian, regional academic communities. The formation of regional academic communities will encourage academics to read each other's work, understand each other, refer to each other and eventually build theories that are not identical to those stemming from Anglo-American economic geographers. The English language is not the problem here. In fact, the use of English is necessary to allow participants with different native languages to achieve equal standing. Without English, there will be regionally dominant language (probably Chinese in 
East Asia), in which case, the problem of Anglophone dominance is repeated at regional scale.

We are aware of many fora which may provide seedbeds for the formation of an East Asian regional community: conferences such as the East Asian Regional Conference in Alternative Geography and the International Conference of Asia Pacific Planning Societies and journals such as Asian Geographer and the International Journal of Urban Sciences may provide the infrastructure for such a community. We realize that our suggestion of regionalization may raise concerns about segregation. However, we believe that a certain level of segregation is beneficial in order to breed different species and contribute to the diversity of the overall ecological system. Infant theories should be shielded from direct competition with more mature theories originating from outside the community. Some of the theories developed under this type of segregation may eventually mature. Some of those mature theories may inspire researchers outside the region - just as regulation theory, French poststructuralist theories and German system theories eventually found their way to the Anglophone world and inspired numerous researchers. Diversity of economic geography can be achieved, we believe, partial segregation through regionalization of academia.

\section{Reference}

Benneworth, P. (2002) Creating new industries and service clusters on Tyneside, Local Economy 17, 313-327. doi:10.1080/ 0269094022000022723

Berry, Brian J. (1968) Interdependency of Spatial Structure and Spatial Behavior: A General Field Theory Formulation. Papers in Regional Science 21(1):205-227 
Boudeville, J. R. Problems of Regional Economic Planning. Edinburgh: Edinburgh University Press, 1966

De Bruijn, P. and Lagendijk, A. (2005) Regional innovation systems in the Lisbon strategy, European Planning Studies 13, 1153- 1172. doi:10.1080/09654310500336519

Feser, E. J. and Luger, M. I. (2003) Cluster analysis as a mode of inquiry: its use in science and technology policymaking in North Carolina, European Planning Studies 11,1124. doi:10.1080/09654310303664

Flanagan, K., Uyarra, E. and Laranja, M. (2011) Reconceptualising the 'policy mix' for innovation, Research Policy 40, 702-713.

Friedmann, J. R. "The Spatial Organization of Power in the Development of Urban Systems," Development and Change, 5 (1975), pp. 12-49.

Hirschman, A. O. (1958) The Strategy of Economic Development (New Haven: Yale University Press).

Krugman, P. (1991). Geography and Trade. MIT Press. 1-142pg.

Myrdat G (1957) Economic theory and under-developed regions. Harper and Row, New York Porter, M.E. (1990). The Competitive Advantage of Nations. New York: The Free Press.

Sonn, J. W., \& Kang, H. (2016). Bureaucratic Rationale and Use of an Academic Concept in Policy-Making: The Rise and Fall of the Regional Innovation System in South Korea. Regional Studies, 50(3), 540-552. https://doi.org/10.1080/00343404.2015.1052061 